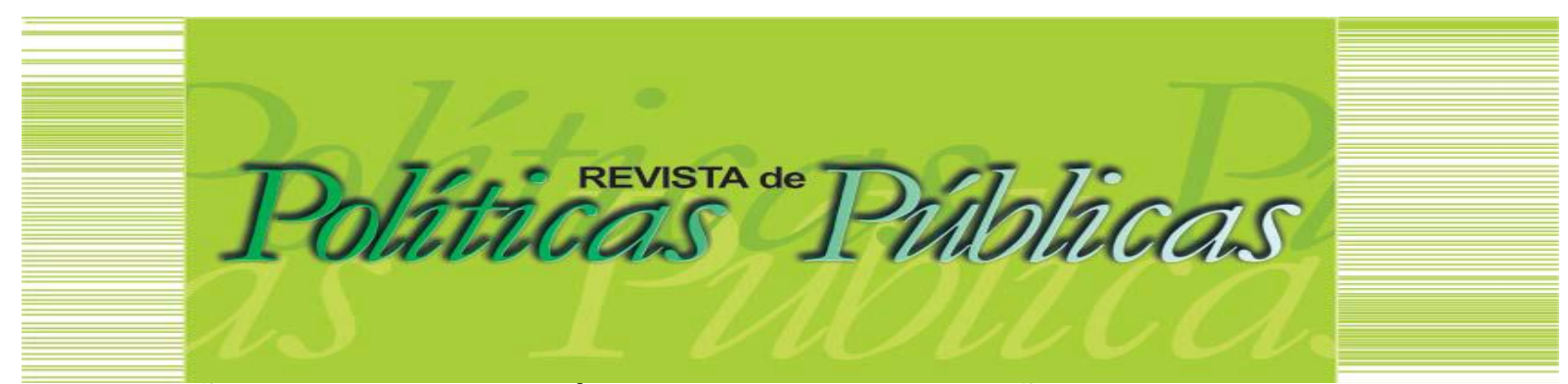

\title{
RELAÇÕES RACIAIS, DEPENDÊNCIA E SUPEREXPLORAÇÃO DA FORÇA DE TRABALHO BRASILEIRA
}

Mizzaely Lacerda1

\section{Resumo}

Este artigo trata das relações raciais no Brasil em sua relação com a dependência brasileira aos países capitalistas mais desenvolvidos e a superexploração da força de trabalho. Para tanto, realiza uma revisão bibliográfica, utilizando autores que versam sobre as particularidades da formação social brasileira, bem como as contribuições de Ruy Mauro Marini sobre a Teoria Marxista da Dependência (TMD). Utiliza, ainda, alguns dados do Instituto Brasileiro de Geografia e Estatística (IBGE) sobre a condição de vida e trabalho de negros e pardos na cena contemporânea. Conclui que a categoria superexploração da força de trabalho, como fundamento da dependência das economias periféricas, é um caminho de análise para conhecer e propor alternativas emancipatórias à situação do trabalhador brasileiro da atualidade que vivencia desigualdades de ordem econômica, social e racial.

Palavras-chave: Relações raciais. Dependência. Superexploração da força de trabalho.

\section{RACIAL RELATIONS, DEPENDENCE AND OVEREXPLOITATION OF THE BRAZILIAN LABOR FORCE}

\section{Abstract}

This article deals with race relations in Brazil in relation to Brazilian dependence on more developed capitalist countries and the overexploitation of the workforce. To this end, it is performed a bibliographic review, using authors who deal with the particularities of Brazilian social formation, as well as Ruy Mauro Marini's contributions about the Marxist Theory of Dependence (TMD). It is also used some data from the Brazilian Institute of Geography and Statistics (IBGE) about the condition of life and work of blacks and browns in the contemporary scene. Concludes that, the category of overexploitation of the workforce, as the basis for the dependence of peripheral economies, is a path of analysis to know and propose emancipatory alternatives to the situation of Brazilian workers today who experience economic, social and racial inequalities. Keywords: Race relations. Dependence. Overexploitation of the workforce.

Artigo recebido em: 28/01/2020 Aprovado em: 28/10/2020 DOI: http://dx.doi.org/10.18764/2178-2865.v24n2p689-702

\footnotetext{
${ }_{1}^{1}$ Assistente Social. Mestranda em Serviço Social pela Universidade Federal do Rio Grande do Norte (UFRN), vinculada ao Grupo de Estudos e Pesquisas em Trabalho, Ética e Direitos (GEPTED). E-MAIL: mizzaelys@gmail.com
} 


\section{INTRODUÇÃO}

Na história da humanidade, diferenças culturais, geográficas, religiosas, raciais e entre os sexos, em diferentes momentos, foram utilizadas para dominar grupos populacionais. Na Grécia, consideravam-se bárbaros todos aqueles que não falassem grego. Em Roma, eram bárbaros os que viviam fora de seus territórios e não possuíam direito: tanto os brancos macedônios, quanto os negros núbios. Na Idade Média, entre os séculos V e XV, os não-cristãos eram povos inferiores na Europa: árabes, africanos, egípcios, chineses, judeus e asiáticos. Por outro lado, a diferença baseada na raça/cor como elemento de justificação da escravização aparece apenas com a colonização da América, Ásia e África pelos europeus, a partir do século XVI (SANTOS, 1941).

A origem de relações raciais violentas, tendo a raça/cor negra como parâmetro, inicia-se com os colonizadores que, visando o domínio de povos e territórios para extração de riquezas, conformam um pensamento colonial racista. A sua origem é, portanto, política e econômica, "não é científica, e o homem não nasce com preconceito". Nesse sentido, "[...] não podemos compreender o aparecimento de um racismo contra o homem de cor sem analisar o problema da expansão colonial [...] e a consequente necessidade de mão de obra escrava" (CARNEIRO, 1983, p. 18).

No Brasil, a expansão colonial e as relações raciais emergentes são os germes dos desdobramentos posteriores. Embora tenham ocorrido modificações na estrutura econômica, com a passagem do sistema escravocrata para 0 trabalho livre, elementos da colonização permanecem ao longo do século XX e, como marcas impregnadas, também reverberam no século XXI, na economia e na cultura.

Dentre essas marcas, destacam-se as relações raciais desiguais, a subordinação às economias centrais e as condições precárias de vida e trabalho, majoritariamente, de negros e pardos no Brasil. A permanência deles na contemporaneidade nos motiva a investigar, no âmbito deste artigo, as relações raciais em sua relação com a dependência brasileira aos países centrais. $A$ articulação entre elas é realizada pela mediação da categoria superexploração da força de trabalho que, para Ruy Mauro Marini (2017), se constitui como o fundamento de uma economia dependente.

\section{RELAÇÕES RACIAIS NA FORMAÇÃO ECONÔMICA E SÓCIO-HISTÓRICA BRASILEIRA}

Em Formação do Brasil Contemporâneo, publicada pela primeira vez em 1942, Caio Prado Júnior é pioneiro ao apresentar uma interpretação marxista para a realidade sócio-histórica brasileira, considerando o passado colonial a base sobre a qual erige o Brasil contemporâneo. No 


\section{RELAÇÕES RACIAIS, DEPENDÊNCIA E SUPEREXPLORAÇÃO DA FORÇA DE TRABALHO BRASILEIRA}

plano econômico, o fato de a produção extensiva continuar voltada para o mercado exterior encontra explicação na herança colonial. A própria constituição do país se dá na condição de uma vasta empresa comercial, subordinada às necessidades do comércio europeu por açúcar, tabaco, café, algodão, ouro e diamantes. Não havia uma economia voltada ao mercado interno, mas uma subordinação ao mercado externo, na Europa, que chegava a determinar, inclusive, quais produtos deveriam ser produzidos (PRADO JÚNIOR, 1961).

Assim, para responder o objetivo comercial, sobretudo da metrópole portuguesa no seu processo de acumulação primitiva ${ }^{1}$, a escravidão moderna brasileira de indígenas e, posteriormente, de negros africanos surge como alicerce do capitalismo mercantil europeu, na busca pela apropriação de territórios e riquezas naturais - o que culminará mais tarde na grande indústria. É aqui onde se encontra a mola propulsora da colonização.

A partir dos novos descobrimentos, a escravidão moderna² ressurge com um novo sentido, diferenciando-se daquela existente na antiguidade clássica. É certo que já havia na África escravização de negros africanos, mas o seu caráter era, essencialmente, patriarcal. 0 trabalho dos escravos voltava-se ao cultivo agrícola para o consumo próprio e ao fornecimento de serviços domésticos aos seus proprietários aristocratas. A forma de apropriação dava-se a partir das guerras entre as tribos nativas, com a escravização dos prisioneiros. É, portanto, a demanda crescente por mão de obra escrava nas colônias que incitará entre os africanos uma captura intensa, numa escala bem maior, de negros para o tráfico, dando o novo sentido para a escravidão moderna, agora predominantemente mercantil - muito embora características patriarcais continuem se perpetuando (GORENDER, 2000).

No Brasil, a apropriação dos corpos dos negros africanos, como propriedade do senhor, ocorre com o objetivo primário voltado ao trabalho produtivo, inicialmente, nas plantações de cana-deaçúcar. No caso das mulheres negras escravizadas, em decorrência da estrutura patriarcal imbricada com o elemento mercantil, suas funções poderiam se vincular ao trabalho nas lavouras, aos serviços domésticos e, ainda, à servidão sexual ao senhor de engenho.

Uma obra clássica que tratou do caráter patriarcal da escravidão brasileira, do ponto de vista da cultura, foi Casa Grande \& Senzala, de Gilberto Freyre, publicada em 1933. Nela, o autor apresenta o lugar da escrava na estrutura escravocrata, dando ênfase na sua função dentro do espaço doméstico, no exercício dos cuidados com os filhos da casa grande e no papel sexual. Contudo, sua análise acaba romantizando e harmonizando as relações e conflitos sociais entre os senhores e as escravas, ao destacar "a doçura" e "o lugar verdadeiramente de honra que [as mães-pretas] ficavam ocupando no seio das famílias patriarcais" (FREYRE, 2003, p. 435, grifo nosso). 
Por outro lado, a obra de Freyre nos entrega um arsenal de informações sobre a violência praticada contra as mulheres escravas (índias e africanas) no período colonial pela via do estupro sexual - ainda que não utilize essa definição - contra mulheres adultas e até adolescentes, "Negras tantas vezes entregues virgens, ainda molecas de doze e treze anos, a rapazes brancos já podres da sífilis das cidades" (FREYRE, 2003, p. 399-400). E, ainda, pela via das agressões físicas praticadas pelas sinhás-moças que, estimuladas pelo ciúme ao descobrir as traições dos senhores com as escravas, mandavam arrancar seus olhos, seios, unhas, dentes, queimavam seus rostos e orelhas.

Particularmente a violência sexual, será apresentada com outra conotação por Freyre (2003). Suaviza-se o seu elemento opressor e reforça-se a miscigenação entre índios, negros e brancos. Ela seria, a seu ver, um fator positivo ao contribuir com o povoamento colonial e a formação da identidade nacional brasileira, gerando o mulato - visto como símbolo de brasilidade. Em direção contrária, Abdias do Nascimento (1978) descreve que ocorreu, na verdade, o estupro da mulher negra como uma forma de genocídio que branqueia a população brasileira e diminui a quantidade de negros. Nas suas palavras,

\begin{abstract}
Para a solução deste grande problema - a ameaça da "mancha negra" - já vimos que um dos recursos utilizados foi o estupro da mulher negra pelos brancos da sociedade dominante, originando os produtos de sangue misto: o mulato, o pardo, o moreno, o pardavasco, o homem-de-côr, o fusco, mencionados anteriormente. 0 crime de violação contra a mulher negra pelo homem branco continuou como prática normal através das gerações. Situado no meio do caminho entre a casa grande e a senzala, o mulato prestou serviços importantes à classe dominante; durante a escravidão ele foi capitão-do-mato, feitor, e usado noutras tarefas de confiança dos senhores, e, mais recentemente, o erigiram como um símbolo da nossa "democracia racial". [...] 0 processo de mulatização, apoiado na exploração sexual da negra, retrata um fenômeno de puro e simples genocídio. Com o crescimento da população mulata a raça negra está desaparecendo sob a coação do progressivo clareamento da população do país (1978, p. 69, grifo nosso).
\end{abstract}

A partir de Nascimento (1978), conseguimos apreender a relação entre a democracia racial e a miscigenação em Freyre (2003, p.33), que chega a afirmar que esta última "corrigiu a distância social [...] entre a casa-grande e a mata tropical; entre a casa-grande e a senzala", promovendo uma "democratização social" no país. A miscigenação, para Freyre (2003), geraria certa igualdade entre negros e brancos. Embora não cite textualmente o termo democracia racial, o seu pensamento fornece subsídios para fortalecer a negação do racismo e das desigualdades sociais e raciais, a partir da construção do mito de uma suposta eliminação da "distância social" entre senhores brancos e escravos negros e indígenas pela miscigenação.

Como nenhuma análise da realidade social se coloca neutra, Freyre se constitui como um intelectual que legitima as oligarquias brasileiras ${ }^{3}$. Assim, partindo da perspectiva da casa grande, harmoniza as relações sociais na colonização e elimina as diferenças de raças. Pretendendo ser e, 


\section{RELAÇÕES RACIAIS, DEPENDÊNCIA E SUPEREXPLORAÇÃO DA FORÇA DE TRABALHO BRASILEIRA}

muitas vezes, sendo visto como antirracista ao eliminar a diferença racial, ele acaba eliminando, ao mesmo tempo, a diferença de classe.

Essas ideias de democracia racial e social, no regime republicano, tiveram um papel essencial para respaldar a igualdade formal brasileira nas novas relações de produção, sobretudo após a Revolução de 1930 com "[...] o fim da hegemonia agrário-exportadora e o início da predominância da estrutura produtiva de base urbano-industrial. Ainda que essa predominância não se concretize em termos da participação da indústria na renda interna senão em 1956" (OLIVEIRA, 2003, p. 35).

Em A integração do negro na sociedade de classes, Florestan Fernandes nos fornece elementos para pensar essa igualdade formal no Brasil, considerando as relações raciais, ao analisar a função social do mito da democracia racial como racismo implícito que se apresenta como necessário no contexto republicano. Na história brasileira, o racismo pode aparecer em alguns momentos de maneira explícita ou implícita, conforme a configuração da estrutura econômica e política do país. $\mathrm{Na}$ época da escravidão, coube a propagação de um racismo explícito para justificar a exploração, à luz dos olhos de todos, por meio da condição inferior do negro e de sua descaracterização como ser humano. Com o abolicionismo e a instauração da República, pela necessidade de aderir ao trabalho assalariado, as relações entre as classes sociais e, dentro delas, entre brancos e negros, passam a se fundamentar, agora, no Estado republicano sob pressão da Inglaterra - potência industrial que exercia hegemonia econômica mundial na época.

No entanto, se na Inglaterra o trabalho assalariado surge fundado na relação de igualdade formal entre vendedores e compradores de força de trabalho ainda na sua gênese, no Brasil, durante 0 período inicial do assalariamento na República Velha (1889-1930), há a particularidade e a contradição de que a massa de trabalhadores disponível no país, formada em sua maioria pela população negra, nem mesmo passa a ser considerada imediatamente como portadora de força de trabalho apta e livre para ser vendida. Estabelece-se, após a abolição da escravatura, uma política de incentivo à entrada de imigrantes brancos europeus, definidos como os mais aptos ao trabalho assalariado.

Diante desse cenário, a função social de afirmar uma democracia racial brasileira na República Nova estava em "[...] isentar aquelas elites, com os círculos sociais que elas representavam - ambos dramaticamente envolvidos na exploração secular do escravo ou do liberto e na política de substituição populacional que eliminou o "negro" da arena econômica -, de "culpas objetivas'" (FERNANDES, 2008, p. 313) e de possíveis reparações. No contexto urbano-industrial, terá o papel de transferir para essa população a responsabilidade de se integrar na nova sociedade de classes, uma vez que todos seriam livres e iguais para galgar melhores condições de vida no mercado de trabalho (FERNANDES, 2008, p. 313). 
O discurso da democracia racial já tinha sido utilizado por Joaquim Nabuco, por exemplo, ainda na escravidão, para convencer os grandes fazendeiros a extinguir o trabalho escravo. No período do desenvolvimento do capitalismo competitivo brasileiro, especialmente a partir da década 1930, ele se colocará como principal base ideológica para as novas relações de produção no Brasil. Nessas novas relações, a força de trabalho negra continuará compondo o pilar do trabalho produtivo do país na condição de subproletariado. Segundo Darcy Ribeiro (1995, p. 231-232, grifo nosso),

Examinando a carreira do negro no Brasil se verifica que, introduzido como escravo, ele foi desde o primeiro momento chamado à execução das tarefas mais duras, como mão-de-obra fundamental de todos os setores produtivos. Tratado como besta de carga exaurida no trabalho, na qualidade de mero investimento destinado a produzir o máximo de lucros, enfrentava precaríssimas condições de sobrevivência. Ascendendo à condição de trabalhador livre, antes ou depois da abolição, o negro se via jungido a novas formas de exploração que, embora melhores que a escravidão, só the permitiam integrar-se na sociedade e no mundo cultural, que se tornaram seus, na condição de subproletariado compelido ao seu antigo papel, que continuava sendo principalmente o de animal de serviço.

As relações raciais estão, desde o princípio, imbricadas dialeticamente nas configurações assumidas pelas relações sociais de produção no Brasil. Ora contribuem para inserir negros no trabalho escravo, ora para substituí-los. Por último, sob os auspícios da democracia racial, respaldam sua integração. Mas, conforme nos mostrou Ribeiro (1995), a integração os coloca na condição de subproletariados. Ou seja, eles estão em maior número na parte da classe trabalhadora - também formada por brancos pobres - que está numa condição de vida e trabalho mais degradante, ocupando os postos de trabalho mais precários, frequentemente ligados ao trabalho braçal, com rendas mais baixas, e sendo maioria na massa de desempregados.

$\mathrm{Na}$ contemporaneidade, o referido cenário pode ser visualizado no estudo intitulado Desigualdades Sociais por Cor ou Raça de 2018, realizado pelo Instituto Brasileiro de Geografia e Estatística (IBGE), cujos dados mostram que, não obstante pretos e pardos representem a maior parte da força de trabalho do país, totalizando 57,7 milhões de pessoas enquanto os brancos totalizam 46,1 milhões, eles continuam inseridos nas maiores taxas de desocupação $(64,2 \%)$ e subutilização 4 $(66,1 \%)$.

E dentre os ocupados, segundo a Pesquisa Nacional de Amostra de Domicílios Contínua (PNAD) referente ao ano de 2018, pretos e pardos apresentam um percentual maior nas ocupações com menores remunerações, concentrando-se nas atividades Agropecuárias $(60,8 \%)$, na Construção $(62,6 \%)$ e nos Serviços domésticos $(65,1 \%)$, as quais possuem rendimentos inferiores à média nacional equivalente a $R \$ 2.163,00$ por mês. Os Serviços Domésticos apresentaram a menor renda média 
mensal com $R \$ 878,00$, em seguida, a Agropecuária com $R \$ 1.300,00$ e, por fim, a Construção com $R \$$ $1.700,00$.

Já no universo das pessoas em situação de pobreza, a Síntese dos Indicadores Sociais (SIS) do IBGE (2019) apontou que a população preta ou parda representa $72,7 \%$ dos pobres, correspondendo a 38,1 milhões de pessoas com rendimento domiciliar entre $R \$ 145,00$ e $R \$ 420,00$ per capita mensais. Em síntese, o conjunto dos dados evidencia que essa população está em maior número submetida à pauperização absoluta,

[...] quando as condições de vida e trabalho dos proletários experimentam uma degradação geral: queda do salário real, aviltamento dos padrões de alimentação e moradia, intensificação do ritmo de trabalho, aumento do desemprego. A pauperização relativa é distinta: pode ocorrer mesmo quando as condições de vida dos trabalhadores melhoram, com padrões de alimentação e moradia mais elevados; ela se caracteriza pela redução da parte que lhes cabe do total dos valores criados, enquanto cresce a parte apropriada pelos capitalistas. [...] Considerados os países capitalistas mais desenvolvidos, registrou-se, historicamente, uma maior ocorrência da pauperização absoluta no desenvolvimento do capitalismo até finais do século XIX; desde então e até à oitava década do século XX, o que neles se constatou foi sobretudo a pauperização relativa. Mas daí não se pode concluir que a pauperização absoluta tenha sido suprimida - pode-se apenas assinalar que, em certas conjunturas históricas, é possível limitar e, mesmo, reverter a sua incidência (NETTO; BRAZ, 2008, p. 135-136, grifo nosso).

Como revelam os autores, a pauperização absoluta não é eliminada, sendo sentida intensamente pelos trabalhadores dos países periféricos. Na realidade periférica brasileira, essa pauperização que atinge pretos e pardos, em suas determinações, só pode ser apreendida levando em consideração o aprofundamento da relação de dependência do Brasil aos países centrais. Tal aprofundamento tem como marco inicial o século XIX com a grande indústria nas nações do centro e prossegue ao longo do século XX com a industrialização dos países periféricos, permanecendo em nosso tempo. É na análise da dependência brasileira, e do seu fundamento: a superexploração da força de trabalho, que conseguimos chegar à essência da degradação das atuais condições de vida e trabalho de negros e pardos no nosso país.

\title{
3 DEPENDÊNCIA E SUPEREXPLORAÇÃO DA FORÇA DE TRABALHO EM RUY MAURO MAIRINI
}

\author{
O subdesenvolvimento da América Latina provém do \\ desenvolvimento alheio e continua alimentando-o. Impotente pela \\ sua função de servidão internacional, moribundo desde que \\ nasceu, o sistema tem pés de barro. ${ }^{5}$
}

Começamos a seção anterior afirmando, brevemente, que o nosso país se forja, desde a época colonial, subordinado às necessidades comerciais dos países europeus. Nessa época, 
demandou-se mão de obra escrava para atuar nas lavouras, fato que permitiu o fomento do tráfico negreiro. Com a Revolução Industrial e a independência política das colônias, a partir do século XIX, ocorre uma transformação nas relações de produção dos países latino-americanos, forçada pela economia central. Concomitantemente, também se processa uma mudança na subordinação que mencionamos outrora, agora marcada pelo aprofundamento da dependência de toda a América Latina ao capitalismo industrial dos países centrais.

Percebendo essa mudança no contexto latino-americano e buscando determinar qual é a especificidade que rege a economia dependente, Ruy Mauro Marini apresenta sua Teoria Marxista da Dependência (TMD), sistematizada em Dialética da Dependência ${ }^{6}$. Em termos gerais, o cientista social brasileiro considera que a situação de subordinação da colônia difere, qualitativamente, da situação de dependência no século XIX. Fundamentalmente, é apenas com a consolidação da grande indústria, e a consequente divisão internacional do trabalho provocada por ela, que a América Latina se articula plenamente com a economia mundial numa relação de dependência, "[...] entendida como uma relação de subordinação entre nações formalmente independentes, em cujo marco as relações de produção das nações subordinadas são modificadas ou recriadas para assegurar a reprodução ampliada da dependência" (MARINI, 2017, p. 327). Vejamos como isso acontece.

No cenário de industrialização do centro, a economia exportadora da América Latina fornece os meios de subsistência, produtos agrícolas e da agropecuária, para abastecer a força de trabalho empregada nas indústrias e nos serviços dos países industriais, ao mesmo tempo em que consome os produtos manufaturados deles. Ocorre, com isso, o aprofundamento da divisão internacional do trabalho, especializando, por um lado, os países centrais enquanto produtores de manufaturas e, por outro, os países latino-americanos como exportadores de alimentos e matérias primas. Mas, a participação da América Latina na economia mundial transcende essa função. Essencialmente,

[...] contribuirá para que o eixo da acumulação na economia industrial se desloque da produção de mais-valia absoluta para a de mais-valia relativa, ou seja, que a acumulação passe a depender mais do aumento da capacidade produtiva do trabalho do que simplesmente da exploração do trabalhador. No entanto, o desenvolvimento da produção latino-americana, que permite à região coadjuvar com essa mudança qualitativa nos países centrais, dar-se-á fundamentalmente com base em uma maior exploração do trabalhador. É esse caráter contraditório da dependência latino-americana, que determina as relações de produção no conjunto do sistema capitalista (MARINI, 2017, p. 328, grifo nosso).

Para capturar mais-valia relativa é necessário aumentar a capacidade produtiva, mas ela "não assegura por si só um aumento da mais-valia relativa". A sua extração acentuada é determinada, de maneira fundamental, pelo "grau da exploração da força de trabalho" (MARINI, 2017, p. 329, grifo 


\section{RELAÇÕES RACIAIS, DEPENDÊNCIA E SUPEREXPLORAÇÃO DA FORÇA DE TRABALHO BRASILEIRA}

nosso) na relação entre o tempo de trabalho excedente - a mais-valia apropriada pelo capitalista - e o tempo de trabalho necessário, que constitui a parte da jornada de trabalho na qual o trabalhador produz o valor dos seus meios de subsistência, os seus bens-salário. Na extração de mais-valia relativa é preciso aumentar o tempo de trabalho excedente e reduzir o tempo de trabalho necessário. Essa redução do tempo de trabalho necessário, por sua vez, só é possível baixando o valor da força de trabalho, alcançada por meio do barateamento dos meios de subsistência.

Para barateá-los, deve-se empregar menos tempo de trabalho para produzi-los, ou seja, deve-se aumentar a produtividade do trabalho pela sua intensificação. Essa intensificação, nos países capitalistas mais desenvolvidos, está hipotecada ao incremento da capacidade produtiva, com investimento em tecnologia e aquisição de matérias primas a baixo custo. Isso permite ao operário produzir mais com o mesmo dispêndio de energia. Como afirmou Marx, a produtividade precisa atingir os ramos que produzem os meios de subsistência para que se consiga uma redução no valor da força de trabalho:

\footnotetext{
Para reduzir o valor da força de trabalho, o aumento da força produtiva tem de afetar os ramos da indústria cujos produtos determinam o valor da força de trabalho, portanto, aqueles ramos que ou pertencem ao círculo dos meios de subsistência habituais, ou podem substituílos por outros meios. Porém, o valor de uma mercadoria não é determinado apenas pela quantidade de trabalho que lhe confere sua forma última, mas também pela massa de trabalho contida em seus meios de produção. 0 valor de uma bota, por exemplo, não é determinado apenas pelo trabalho do sapateiro, mas também pelo valor do couro, do piche, do cordão etc. Portanto, a queda no valor da força de trabalho também é causada por um aumento na força produtiva do trabalho e por um correspondente barateamento das mercadorias naquelas indústrias que fornecem os elementos materiais do capital constante, isto é, os meios e os materiais de trabalho para a produção dos meios de subsistência (MARX, 2014, p. 485, grifo nosso).
}

Diferentemente dos países centrais, nos países latino-americanos, o aumento do rendimento pela intensificação do trabalho não ocorre hipotecada, de modo fundamental, ao incremento da capacidade produtiva. Na verdade, se realiza por um maior grau de exploração dos trabalhadores, com maior dispêndio de energia exigido, especialmente, nas indústrias agrícola e extrativista. E é essa exploração intensificada de forma particular, na América Latina, que incidirá na oferta barateada de meios de subsistência, assumindo o papel essencial de "[...] reduzir o valor real da força de trabalho nos países industriais, permitindo assim que o incremento da produtividade se traduza ali em taxas de mais-valia cada vez mais elevadas" (MARINI, 2017, p. 329). Do mesmo modo, o fornecimento de matérias primas barateadas, pelos países latino-americanos, possibilita equilibrar a composição-valor do capital, impedindo o declínio da taxa de lucro ao reduzir o valor do capital constante nos países do centro. 
Nessas trocas entre as nações, Marini (2017) revela que ocorre uma troca desigual. Opera-se uma transferência de valor aos países capitalistas mais desenvolvidos. De um lado, os países centrais que, possuindo maior capacidade produtiva, possuem um preço de produção menor, mas não diminuem o preço de mercado de suas manufaturas. E, de outro, os países latino-americanos, que compram tais manufaturas acima de seu valor e vendem bens primários a um preço menor.

A transferência de valor pode ocorrer, ainda, por meio da entrada de investimentos do capital estrangeiro dentro dos países latino-americanos, com instalações de empresas transnacionais atraídas pela mão de obra com salários rebaixados, recursos naturais disponíveis e estímulos estatais como infraestrutura e isenção de impostos, por exemplo. Dessa forma, essas empresas canalizam o valor gerado para o seu país de origem.

Para compensarem a perda de valor gerada nessas transferências, os países latinoamericanos recorrem à superexploração do trabalhador. Tal superexploração, em Marini (2017), pode ocorrer pela adoção de três métodos de ampliação do trabalho excedente: 1) intensificação do trabalho, com aumento de mais-valia extraída pela maior exploração da força física do trabalhador; 2) prolongação da jornada de trabalho; e 3) expropriação de parte do trabalho necessário do trabalhador, colocando limites na reprodução de sua força de trabalho ao retirar dele a possibilidade de consumir 0 necessário para a sua reprodução. Noutras palavras, o seu salário é fixado abaixo do indispensável.

Assumindo essas características, o sentido da categoria superexploração em Marini (2017) não é idêntico ao de mais-valia absoluta, porque engloba também um método de captura de mais-valia relativa: 0 aumento da intensidade do trabalho com vistas a reduzir o tempo de trabalho necessário e aumentar o trabalho excedente. Lembremos que em Marx, a mais-valia absoluta é extraída pela extensão da jornada de trabalho - configuração que aparece fortemente no período da grande indústria. Mas, existem limites físicos e legislativos que, envoltos pelos embates políticos entre capitalistas e trabalhadores, limitam a jornada de trabalho. Com essa limitação,

[...] a taxa de mais-valor só pode ser aumentada por meio de uma mudança relativa da grandeza de suas partes constitutivas, do trabalho necessário e do mais-trabalho, o que, por sua vez, pressupõe, para que o salário não caia abaixo do valor da força de trabalho, uma mudança na produtividade ou intensidade do trabalho (MARX, 2014, p. 709-710, grifo nosso).

A superexploração em Marini (2017), na realidade, combina diferentes formas de exploração, com a particularidade de que a intensificação do trabalho ocorre pela via de uma "[...] maior exploração da força física do trabalhador, em contraposição à exploração resultante do aumento de sua produtividade, e tende normalmente a se expressar no fato de que a força de trabalho se remunera abaixo de seu valor real" (MARINI, 2017, p. 350, grifo nosso). É essa a especificidade e uma das 


\section{RELAÇÕES RACIAIS, DEPENDÊNCIA E SUPEREXPLORAÇÃO DA FORÇA DE TRABALHO BRASILEIRA}

grandes contribuições trazida pelo autor. Se nos países centrais altera-se a produtividade e a intensidade do trabalho de modo que o salário não cai abaixo do valor da força de trabalho, nos países latino-americanos ocorre um rebaixamento salarial como um dos mecanismos para compensar a perda de valor gerada nas transferências às economias centrais.

Outra particularidade é que mesmo aumentando a capacidade produtiva, essa superexploração continua se perpetuando. No Brasil, em meados da década de 1950, muito se apostou na ideia de que o país poderia alcançar os países capitalistas mais desenvolvidos, particularmente os Estados Unidos da América (EUA), e melhorar a condição de vida e trabalho da população brasileira por meio do desenvolvimento industrial.

Contudo, como bem elucida Marini (2017), a própria industrialização foi forjada numa relação de dependência, com investimento maciço de capital estrangeiro na indústria pesada, gerando transferência de valor para as economias centrais. Esse momento de fomento industrial coincide com a etapa imperialista dos países do centro. Devido o alto grau de concentração e centralização de capital no pós-guerra ${ }^{7}$, esses países vão forçar novos campos de investimentos na periferia para escoar excedente econômico.

Mas, mesmo com importações de maquinário e matérias primas - permitindo uma elevação na produtividade - e exportações de manufaturas, não foi suficiente para romper com os salários defasados e precarização do trabalho no Brasil. Ao contrário, a economia industrial continuou reproduzindo mais dependência e compensando a transferência de valor com mais superexploração.

Nesse sentido, Ruy Mauro Marini chama nossa atenção ao destacar que o crescimento da exploração, na medida em que aumenta a força produtiva do trabalho, é inerente à lei geral da acumulação capitalista. Todavia, o modo como essa lei incide na periferia é particular. Dentro de relações de superexploração e dependência, os países periféricos são impossibilitados de transitarem da extração de mais-valia absoluta à mais-valia relativa como ocorreu nos países centrais. $\mathrm{E}$ isso, evidentemente, guarda uma conexão com o passado colonial escravocrata: "A importância do regime de produção escravista na determinação da atual economia de alguns países latino-americanos, como, por exemplo, Brasil, é um fato que não pode ser ignorado" (MARINI, 2017, p. 346).

\section{CONSIDERAÇÕES FINAIS}

A partir desses elementos que discutimos, torna-se possível, agora, gerarmos uma breve síntese sobre as relações raciais em sua articulação com a dependência e a superexploração da força de trabalho brasileira. Eles permitem definir alguns momentos da formação econômica e sócio- 
histórica do Brasil que não são os únicos, mas configuram-se como decisivos para lançar luz nesse contexto.

O primeiro é a fase germinal dos desdobramentos posteriores. Trata-se da colonização, cuja dinâmica apoiava-se no trabalho escravo acompanhado por relações raciais marcadas por um racismo explícito, com destaque para a condição inferior do negro e a sua negação como ser humano. A economia e a cultura que conformaram a sociedade escravocrata funcionaram voltadas à canalização de riqueza para a Europa. Esse momento foi decisivo para possibilitar que as metrópoles transitassem do capitalismo mercantil ao industrial, com base na produção gerada pelo escravo via jornadas de trabalho extensas e exaustivas.

O segundo, por sua vez, compreende a fase imperial (1822-1889), a partir da independência política do Brasil. É nesse período que se instaura de maneira particular a dependência brasileira aos países centrais, na divisão internacional do trabalho, com o surgimento da grande indústria nestes últimos. A economia agroexportadora, ainda apoiada na mão de obra formada por escravos negros, fornece alimentos e matérias-primas necessárias para aumentar a capacidade produtiva das potências industriais, especialmente da Inglaterra.

O terceiro momento decisivo refere-se aos anos da República Velha (1889-1930). Com 0 abolicionismo e a instauração do trabalho assalariado, a força de trabalho da população negra aparece no cenário brasileiro como inapta para as novas relações de produção. O pensamento colonial espraia a ideia de que trabalhadores negros representam um atraso e, portanto, seria necessário importar trabalhadores europeus, brancos, para desenvolver a economia agroexportadora do país. Há a entrada maciça de imigrantes pobres vindos da Europa e, ao mesmo tempo, a geração de uma grande massa de negros sem trabalho, se amontoando nas cidades.

Simultaneamente, assiste-se no cenário mundial a entrada do capitalismo na sua fase monopolista. O sistema escravocrata voltado ao desenvolvimento da economia agroexportadora contribuiu com a transição dessa nova etapa. Como afirmou Marini (2017), a América Latina possibilita o deslocamento, nas economias centrais, da acumulação de mais-valia absoluta para a mais-valia relativa. Esta última predominará na era monopólica, o que não significa dizer que a mais-valia absoluta tenha desaparecido, pelo contrário. Nos países latino-americanos como o Brasil, há uma combinação de extração de mais-valia absoluta e relativa caracterizando uma superexploração particular que continua alimentando o desenvolvimento das economias centrais e reproduzindo a relação de dependência.

Esse quadro de superexploração garante a reprodução da pauperização absoluta que, no caso brasileiro, vem a atingir em sua maioria negros e pardos - trata-se de uma especificidade de sua 
formação socioeconômica. A pauperização absoluta é, portanto, a parte visível da superexploração da força de trabalho que, combinando maior exploração da força física e expropriação dos salários, mantém vivos os resquícios do passado colonial brasileiro. As novas/velhas relações raciais respaldadas no mito da democracia racial, como racismo implícito que ganha força na década de 1930, são a base ideológica necessária para o estabelecimento de uma igualdade formal no Brasil e uma nova inserção da força de trabalho da população negra em condições de superexploração para compensar a transferência de valor às economias centrais.

A nosso ver, levar em consideração a permanência da extração de mais-valia absoluta e da pauperização absoluta no marco das relações de dependência, pela mediação da categoria da superexploração da força de trabalho como fundamento dessas relações, é um caminho de análise para conhecer e propor alternativas emancipatórias à situação do trabalhador brasileiro na atualidade, sobretudo, daquele que traz na sua pele um passado que se reatualiza no presente na economia e na cultura na forma de desigualdades econômicas, sociais e raciais.

\section{REFERÊNCIAS}

BASTOS, Elide Rugai. As criaturas de prometeu. São Paulo: Global, 2006.

CARNEIRO, Maria Luiza Tucci. Preconceito racial no Brasil-Colônia: os cristãos-novos. São Paulo: Brasiliense, 1983.

FERNANDES, Florestan. A integração do negro na sociedade de classes. 5. ed. São Paulo: Globo, 2008. (Obras reunidas de Florestan Fernandes).

FREYRE, Gilberto. Casa-grande \& senzala: formação da família brasileira sob o regime da economia patriarcal. 48. ed. São Paulo: Global, 2003.

GALEANO, Eduardo. As veias abertas da América Latina. Tradução de Sergio Faraco. Porto Alegre: LP\&M editores, 2010.

GORENDER, Jacob. Brasil em preto e branco. São Paulo: Senac, 2000.

IBGE. Desigualdades sociais por cor ou raça no Brasil. Rio de Janeiro: IBGE, 2019. (Série Estudos e pesquisas - Informação demográfica e socioeconômica, n. 41).

Síntese de indicadores sociais: uma análise das condições de vida da população brasileira. Rio de Janeiro: IBGE, 2019. (Série Estudos e pesquisas - Informação demográfica e socioeconômica, n. 40).

MARINI, Ruy Mauro. Dialética da dependência. In: Germinal: Marxismo e educação em debate, Salvador, v. 9, n. 3, p. 325-356, dez. 2017. 
MANDEL, Ernest. 0 capitalismo tardio. Tradução de Carlos Eduardo Silveira Matos, Regis de Castro Andrade e Dinah de Abreu Azevedo. São Paulo: Abril Cultural, 1982.

MARX, Karl. 0 capital: crítica da economia política. Tradução de Regis Barbosa e Flávio R. Kothe. Tomo 2. São Paulo: Abril Cultural, 1984.

O capital: crítica da economia política. Livro I: o processo de produção do capital. Tradução de Rubens Enderle. São Paulo: Boitempo, 2014.

NASCIMENTO, Abdias do. 0 genocídio do negro brasileiro: processo de racismo mascarado. Rio de Janeiro: Paz e Terra, 1978.

NETTO, José Paulo; BRAZ, Marcelo. Economia Política: uma introdução crítica. São Paulo: Cortez, 2008. (Biblioteca básica de serviço social).

OLIVEIRA, Francisco de. Crítica à razão dualista: o ornitorrinco. São Paulo: Boitempo, 2003.

PRADO JÚNIOR, Caio. Formação do Brasil contemporâneo: colônia. 6. ed. São Paulo: Brasiliense, 1961.

RIBEIRO, Darcy. 0 povo brasileiro: a formação e o sentido do Brasil. 2. ed. São Paulo: Companhia das Letras, 1995.

SANTOS, Joel Rufino dos. 0 que é racismo. São Paulo: Brasiliense, 1941. (Coleção Primeiros Passos).

\section{Notas}

1 Nos termos de Marx, "A descoberta das terras do ouro e da prata, na América, o extermínio, a escravização e o enfurnamento da população nativa nas minas, o começo da conquista e pilhagem das Índias Orientais, a transformação da África em um cercado para a caça comercial às peles negras marcam a aurora da era de produção capitalista. Esses processos idílicos são momentos fundamentais da acumulação primitiva. [...] baseiam-se, em parte, sobre a mais brutal violência, por exemplo, o sistema colonial” (1984, p. 285).

${ }^{2}$ Estabelece-se, após a Idade Média, a partir do final do século XV e início do século XVI, durante a Idade Moderna.

${ }^{3}$ Como disse Bastos (2006, p. 48), "Nunca, antes da década de 1930, os setores dominantes agrários tiveram tão grande ideólogo. E, nunca, uma interpretação sobre os mesmos tão grande sucesso".

${ }^{4}$ Aqui se inserem tanto os desocupados que procuram trabalho e não encontram, quanto os trabalhadores subocupados por insuficiência de horas e a força de trabalho potencial, composta por aqueles que não estão nem ocupados nem desocupados, mas possuem capacidade de realizar trabalho disponível (IBGE, 2019).

${ }_{5}^{5}$ GALEANO, Eduardo. As veias abertas da América Latina. Tradução de Sergio Faraco. Porto Alegre: LP\&M editores, 2010.

${ }^{6}$ O Ensaio foi escrito durante o seu exílio no México, no período da ditadura civil-militar brasileira, cuja primeira publicação ocorre em 1973 por uma editora mexicana.

${ }^{7}$ Para uma análise aprofundada desse período, consultar: Mandel (1982). 